\title{
Maternal demographic and clinical variables do not predict intrauterine contraception placement: evidence for postplacental intrauterine contraception placement
}

\author{
Jean Hansen, DO ${ }^{1}$ Mark K. Santillan, MD ${ }^{1}$ Barbara J. Stegmann, MD, MPH, ${ }^{2}$ Tina C. \\ Foster, MD, MPH, MS, ${ }^{3}$ Abbey J. Hardy-Fairbanks, MD ${ }^{1}$
}

Keywords: Intrauterine devices, IUD, IUC, postpartum, contraception, Mirena

\begin{abstract}
Objective: Determine if specific demographic and clinical variables are associated with intrauterine contraception (IUC) placement by eight weeks postpartum.

Methods: This retrospective cohort study included all patients who delivered at Dartmouth-Hitchcock Medical Center (DHMC) (July-December 2008) who identified IUC as their preferred postpartum contraceptive method. Medical records of patients identified from the birth log were reviewed for preferred contraception, demographics, medical, obstetric, and social histories, as well as payer status. Chi-squared analysis was performed for categorical variables, and Mann-Whitney $U$ test was used for continuous variables. Nonparametric continuous variables were categorized for regression modeling.
\end{abstract}

Results: 224 (34\%) patients who delivered identified IUC as their preferred method of postpartum contraception. Of these, 94 (49.7\%) women had an IUC placed by 8 weeks postpartum. In univariate analyses comparing those who received an IUC versus those patients who did not, only mean interdelivery interval in months (39.7 vs. 35.5, $p=0.027$ ) and mean gravidity (2.3 vs. 2.8, $p=0.036)$ were statistically significant. In multivariate regression modeling, no variables were significantly associated with IUC placement.

Conclusions: While statically significant interdelivery interval and gravidity are not likely to be clinically significant. Multivariate modeling failed to identify a model associated with IUC placement suggesting that postpartum IUC placement is not well predicted by patient variables. Lack of identifying factors may support offering postplacental IUC placement to all patients who indicate IUC as their preferred contraceptive method.

\footnotetext{
${ }^{1}$ University of lowa Hospitals and Clinics, Department of Obstetrics and Gynecology, lowa City, lowa

${ }^{2}$ Merck Research Laboratories, New Jersey

${ }^{3}$ Dartmouth-Hitchcock Medical Center, Lebanon, New Hampshire
}

Please cite this paper as: Hansen J, Santillan MK, Stegmann BJ, Foster T, Hardy-Fairbanks AJ . Maternal demographic and clinical variables do not predict intrauterine contraception placement: Evidence for postplacental intrauterine contraception placement. Proc Obstet Gynecol. 2014;4(2): Article 4 [ 7 p.]. Available from: http://ir.uiowa.edu/pog/. Free full text article.

Corresponding author: Abbey J. Hardy-Fairbanks, MD, University of lowa Hospitals and Clinics, Department of Obstetrics and Gynecology, 200 Hawkins Drive, Iowa City, IA 52242. Telephone: 319-356-2291. abbey-hardyfairbanks@uiowa.edu.

Financial Disclosure: The authors report no conflict of interest.

Copyright: (c) 2014 Hansen, et al. This is an open-access article distributed under the terms of the Creative Commons Attribution License, which permits unrestricted use, distribution, and reproduction in any medium, provided the original author and source are credited. 


\section{Introduction}

Despite counseling to the contrary many women resume sexual intercourse prior to their 6 week postpartum visit; this occurs independently of vaginal or cesarean delivery, and whether or not episiotomy was performed. ${ }^{1}$ In nonbreastfeeding women, ovulation may resume as early as 27 days postpartum and occurs on average four weeks postpartum. ${ }^{1}$ In exclusively breastfeeding women, ovulation typically resumes later, ranging from 189 to 259 days. ${ }^{1,2}$ Women who supplement and introduce solid foods in addition to breast feeding may ovulate earlier than those exclusively breastfeeding. Up to two-thirds of women ovulate prior to their first vaginal bleeding, therefore, bleeding cannot be used as a reliable indicator of ovulation. ${ }^{2}$

There are a variety of contraceptive methods that can be employed immediately postpartum in both breastfeeding and non-breastfeeding women. Intrauterine contraception (IUC) is typically placed at 6-10 weeks postpartum. However if a patient's primary plan for contraception is IUC, and she resumes ovulation prior to her postpartum visit or does not attend her postpartum visit, she remains unprotected against pregnancy. Recent evidence supports postplacental placement of IUCs, defined as placement within 10 minutes of placental separation. ${ }^{3-5}$ However, the incidence of expulsion is increased over interval placement, with the most commonly cited rates as $5 \%$ after interval placement and $12 \%$ after postplacental placement. ${ }^{3,6,7}$

The purpose of this study was to identify demographic characteristics of women who identified IUC as their preferred method of contraception, and determine whether the IUC was actually placed by eight weeks postpartum. A common perception among providers is that patients at "high-risk" for not returning for IUC can be identified. We hoped to identify specific high risk characteristics and thus ideal candidates for postplacental IUC placement despite the increased expulsion rate.

\section{Methods}

A retrospective cohort study was designed that included all deliveries occurring at Dartmouth-Hitchcock Medical Center (DHMC) between July and December 2008. The study activities were reviewed and approved by the Institutional Review Board at DHMC. The DHMC birth log was used to identify all patients who delivered during the study period. Medical records were reviewed to identify women who desired IUC as their preferred method. Contraception plans are routinely noted in the discharge summary and reflect expressed preference at the time of discharge (which may differ from what is found in the antepartum record). For those women who desired IUC, medical records were further reviewed to determine if they had undergone IUC placement by 8 weeks postpartum. Demographic characteristics included age at delivery, parity, gravity, gestation at delivery, mode of delivery, interpregnancy interval (if applicable), marital status, type of provider (nurse midwife or obstetrician) number of prenatal visits, insurance status, and breastfeeding at discharge. Postpartum visit notes were reviewed for IUC insertion or alternant method of 
contraception.

Statistical analysis of compiled data was completed to assess for significant demographic factors associated with lack of IUC insertion by eight weeks postpartum using a standard significant $p$ value of 0.05 . Chi-square analysis was performed for all categorical variables. For continuous variables, Mann-Whitney $\mathrm{U}$ tests were performed. For regression modeling, nonparametric continuous variables (such as gravidity and gestational age at delivery) were categorized. Regression analysis was used to determine variables associated with IUC placement, while controlling for all other variables.

\section{Results}

224 of 651 women (34\%) who delivered during the study period identified IUC as their preferred method of postpartum contraception. Among the cohort of women delivered the most commonly identified postpartum contraception choice was oral contraception (including progesterone only oral contraception), which was chosen by $25 \%$ of women. Barrier methods, both female and male, were identified by $16.3 \%$, female sterilization by $9.2 \%$, male sterilization $4.5 \%$, exclusive breast feeding $0.5 \%$, and progesterone implant 0.3\%. 13.4\% had no preferred contraception choice at discharge.

A total of 189 women delivered who requested IUC for postpartum contraception planned follow-up at our facility (see Figure 1). 55 (29.1\%) of these women did not present for their post-partum visit. Of the 134 women who returned for follow-up, 94 received IUC; of these, $84(89.3 \%)$ had a levonorgestrel intrauterine system and $10(10.7 \%)$ had a copper T380A device placed. Thus, half of the women who planned follow-up and IUC placement postpartum at DHMC did not receive an IUC by eight weeks postpartum. Of the women who presented for their postpartum visit, 18 (11.3\%) opted for oral contraceptive pills, 39 (24.4\%) barrier methods, and 24 (15.0\%) opted for no contraception. Three women wanted an IUC at their visit, but were unable due to having unprotected intercourse prior to their postpartum visit.

Demographic characteristics of women with planned follow-up at our facility who did not have an IUC placed were compared to women who did have an IUC placed (Table 1). There was no difference in the number of women who were married, insurance status, or breastfeeding at discharge. Prenatal care service (midwife vs physician) and mode of delivery (cesarean versus vaginal) were also not different between the groups. The average age of women who had their IUC placed by 8 weeks postpartum was 27.0 years and for those who did not have an IUC it was 27.9 years $(p=.306)$. Statistical analysis excluding those who were lost to followup due to receiving postpartum care at another facility, revealed gravidity was significantly $(p=0.036)$ higher in those women who successfully had an IUC placed prior to 8 weeks postpartum. Longer interdelivery interval (39.7 vs. $35.5, p=0.027)$ and longer gestational age (279.4 versus 266.7 days, $p=0.031$ ) was associated with higher likelihood of having an IUC inserted postpartum. All other variables remained nonsignificant. 


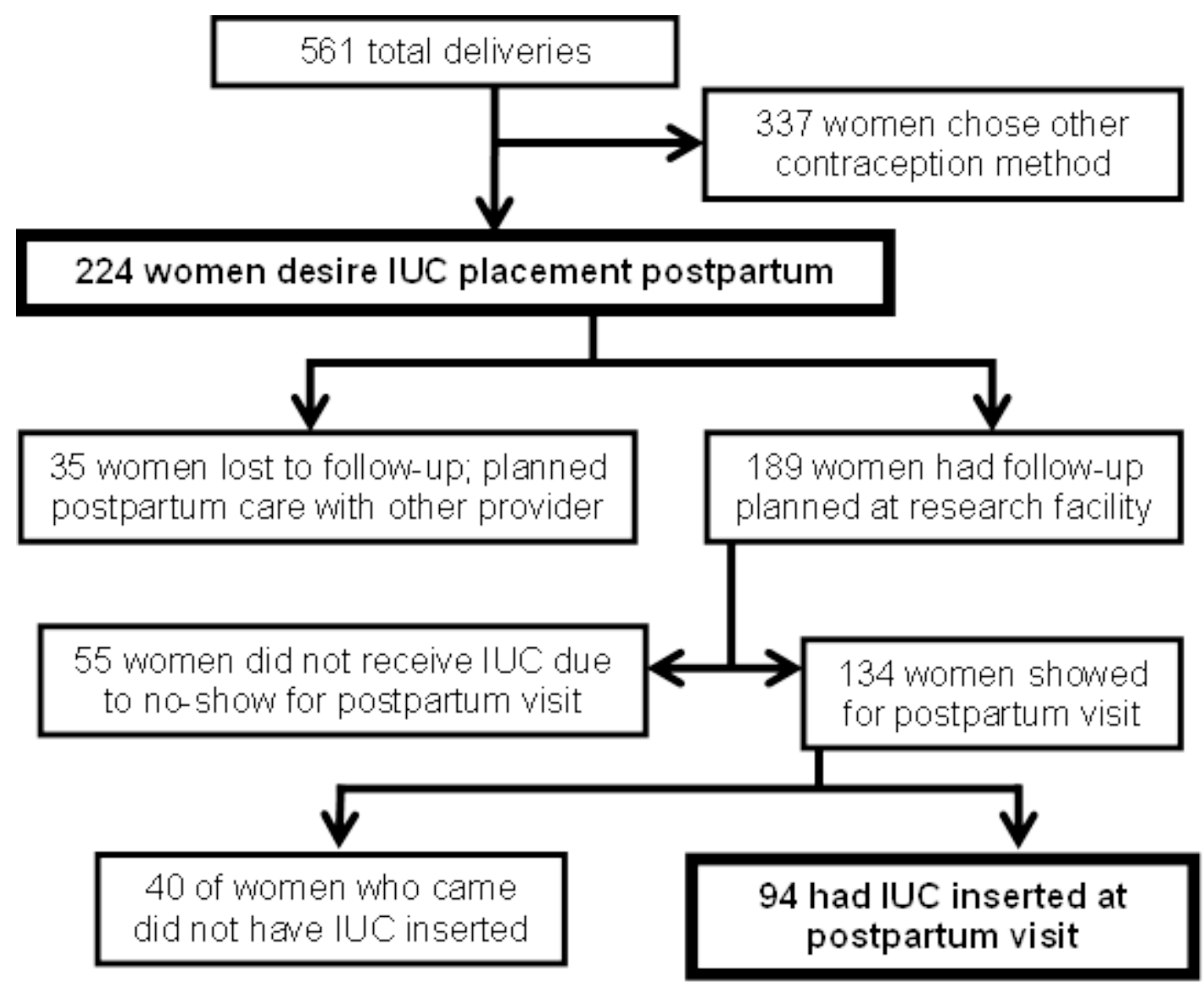

\section{Figure1. Subject flow diagram}

Using a univariate regression model, the unadjusted odds ratios for each demographic variable were calculated and demonstrated that age, mode of delivery, marital status, percent of office visits arrived, insurance status, provider type and gestational age showed no impact on whether or not a patient received her IUC by 8 weeks postpartum. Finally an adjusted odds ratio, controlling for other variables via multivariate analysis, likewise showed no significant difference in gravidity, age, mode of delivery, insurance status, provider type or gestational age.

\section{Discussion}

We hypothesized that the demographic characteristics of women who identified IUC as their desired postpartum contraceptive method but did not receive that method by 8 weeks would be distinct from the characteristics of those women who did have an IUC placed by 8 weeks postpartum. Our study did identify statistically significant univariate differences in inter-delivery interval, gravidity, and gestational age at delivery. Gestational age differences shown in this study are unlikely to be clinically significant with only four days difference between groups. Women with 
longer interdelivery interval are potentially more likely to have been compliant or sought postpartum contraception in the past. Multivariate modeling demonstrated no significant model associated with IUC placement, suggesting that postpartum IUC placement is not well predicted by patient demographic characteristics. Limitations of this study include its small size and the relative homogeneity of the population (predominantly Caucasian). The percentage of those who successfully completed IUC placement is consistent with other studies. ${ }^{8,9}$

Table 1. Demographic data

\begin{tabular}{|lccc|}
\hline Demographic Variable & IUC placed $(\mathbf{n}=\mathbf{9 4})$ & IUC not placed $(\mathbf{n}=\mathbf{9 5})$ & P-value \\
\hline Married & 57 & 55 & 0.883 \\
\hline State sponsored insurance & 37 & 39 & 0.881 \\
\hline Private insurance & 51 & 53 & 0.822 \\
\hline Self-pay & 12 & 15 & 0.185 \\
\hline Breastfeeding at discharge & 69 & 66 & 0.755 \\
\hline CNM provider & 47 & 42 & 0.589 \\
\hline MD provider & 53 & 58 & 0.589 \\
\hline Cesarean delivery & 28 & 32 & 0.632 \\
\hline Vaginal delivery & 72 & 68 & 0.629 \\
\hline Age & 27.01 years & 27.95 years & 0.306 \\
\hline Gestational age & 270.4 days & 266.7 days & 0.031 \\
\hline $\begin{array}{l}\text { Interdelivery interval } \\
\text { (if applicable) }\end{array}$ & 39.7 months & 35.4 months & 0.056 \\
\hline \% visits arrived & $79.6 \%$ & $76.7 \%$ & 0.017 \\
\hline
\end{tabular}

Women discharged from the hospital following delivery without a reliable form of contraception are at risk for an unplanned pregnancy. Adequate birth spacing is essential in preventing morbidity and mortality for both infant and mother. Short interpregnancy interval is associated with increased risk of preterm birth and neonatal death. ${ }^{10,11}$ Additionally, in women with a history of cesarean section, a short interpregnancy interval, especially less than 6 months, is associated with a significantly increased risk of uterine rupture. ${ }^{12}$

Our findings support the prior supposition that the postpartum visit itself is not a reliable intervention for initiation of contraception. ${ }^{1}$ Rather, contraception is most effective when initiated prior to discharge from the hospital. This is especially true for women who do no not breastfeed, or for those who initially intend to breastfeed but convert to formula feeding early on, because they will not have lactational amenorrhea. Our data therefore support offering post-placental IUC placement to all patients who indicate IUC as their preferred contraceptive method. The immediate postpartum period is an ideal time for IUC insertion, given that recently delivered women are often 
highly motivated to use contraception, are known not to be pregnant, and the hospital setting offers convenience for both the patient and healthcare provider.

\section{References}

1. Speroff L, Mishell DR Jr. The postpartum visit: it's time for a change in order to optimally initiate contraception. Contraception. 2008 Aug;78(2):90-8. doi:

10.1016/j.contraception.2008.04.005.

Epub 2008 Jun 12. PubMed PMID: 18672108.

2. Campbell OM, Gray RH. Characteristics and determinants of postpartum ovarian function in women in the United States. Am J Obstet Gynecol. 1993 Jul;169(1):55-60.

http://dx.doi.org/10.1016/0002-

9378(93)90131-2. PubMed PMID: 8333476.

3. Chen BA, Reeves MF, Hayes JL, Hohmann HL, Perriera LK, Creinin MD. Postplacental or delayed insertion of the levonorgestrel intrauterine device after vaginal delivery: a randomized controlled trial. Obstet Gynecol. 2010 Nov;116(5):1079-87. doi: 10.1097/AOG.0b013e3181f73fac. PubMed PMID: 20966692.

4. American College of Obstetricians and Gynecologists. ACOG Practice Bulletin No. 121: Long-acting reversible contraception: Implants and intrauterine devices. Obstet Gynecol. 2011 Jul;118(1):184-96. doi: 10.1097/AOG.0b013e318227f05e. PubMed PMID: 21691183.

5. Centers for Disease Control and Prevention (CDC). U S. Medical Eligibility Criteria for Contraceptive Use, 2010. MMWR Recomm Rep. 2010 Jun 18;59(RR-4):1-86. PubMed PMID: 20559203.
6. Kapp N, Curtis KM. Intrauterine device insertion during the postpartum period: a systematic review. Contraception. 2009 Oct;80(4):327-36. doi: 10.1016/j.contraception.2009.03.024. Epub 2009 Aug 29. PubMed PMID: 19751855.

7. Grimes DA, Lopez LM, Schulz KF, Van Vliet HA, Stanwood NL. Immediate postpartum insertion of intrauterine devices. Cochrane Database Syst Rev. 2010 May 12;(5):CD003036. doi: 10.1002/14651858.CD003036.pub2. PubMed PMID: 20464722.

8. Eroğlu K, Akkuzu G, Vural G, Dilbaz B, Akin A, Taşkin L, Haberal A. Comparison of efficacy and complications of IUD insertion in immediate postplacental/early postpartum period with interval period: 1 year follow-up. Contraception. 2006 Nov;74(5):376-81. Epub 2006 Sep 15. PubMed PMID: 17046378.

9. Ogburn JA, Espey E, Stonehocker J. Barriers to intrauterine device insertion in postpartum women. Contraception. 2005 Dec;72(6):426-9. http://dx.doi.org/10.1016/j.contraception. 2005.05.016. Epub 2005 Aug 9. PubMed PMID: 16307964.

10. DeFranco EA, Stamilio DM, Boslaugh SE, Gross GA, Muglia LJ. A short interpregnancy interval is a risk factor for preterm birth and its recurrence. Am J Obstet Gynecol. 2007 Sep;197(3):264.e1-6. DOI: 10.1016/j.ajog.2007.06.042. PubMed PMID: 17826413.

11. Smith GC, Pell JP, Dobbie R. Interpregnancy interval and risk of preterm birth and neonatal death: retrospective cohort study. BMJ. 2003 Aug 9;327(7410):313. http://dx.doi.org/10.1136/bmj.327.7410.3 13. Erratum in: BMJ. 2003 Oct 11;327(7419):851.

http://dx.doi.org/10.1136/bmj.327.7419.8 51. PubMed PMID: 12907483. 
12. Stamilio DM, DeFranco E, Paré E, Odibo AO, Peipert JF, Allsworth JE, Stevens E, Macones GA. Short interpregnancy interval: risk of uterine rupture and complications of vaginal birth after cesarean delivery. Obstet Gynecol. 2007 Nov;110(5):1075-82. http://dx.doi.org/10.1097/01.AOG.00002 86759.49895.46. PubMed PMID: 17978122. 